\title{
Perspectives of academia on advancing the agenda of Universal Health Coverage in India
}

\author{
Anjali Sharma ${ }^{1}$, Sanjay Zodpey ${ }^{2}$
}

${ }^{1}$ Program Officer - Academic Programs; ${ }^{2}$ Director, Public Health Education; Public Health Foundation of India, New Delhi, India

\begin{abstract}
Universal health coverage (UHC) is currently at the center of discussion to strengthen health systems and improve health outcomes. The design and delivery of UHC requires an active engagement of various stakeholders viz. policy makers, program managers, civil society, private sector, academia and health professional associations. However, limited information is available on engagement of academia in discussions related to UHC. This study attempted to examine the perspectives of academia on advancing the agenda of UHC in India. A cross-sectional qualitative study was conducted with 62 stakeholders which included deans and senior faculty from 17 government and 15 private medical institutions across India, using a semi-structured questionnaire. Data analysis was done through free listing of responses, domain evolution and using qualifiers for semi-quantitative expressions. Clarity on concept of UHC and awareness on UHC developments was found low amongst stakeholders. It was strongly believed that not just tertiary care services but primary health care is more critical for UHC to succeed. Besides the responsibility of government, engaging other organizations was underlined. Approximately half of the respondents mentioned that their organization can support the provision of providing promotive, preventive, curative, and rehabilitative health services to achieve UHC. Stakeholders also felt that the tax-based and private health insurance can act complementary to each other, and should be promoted to improve health services coverage. Findings suggest that there is a strong need for engagement of academia for marching towards the goal of UHC.
\end{abstract}

Keywords: Universal Health Coverage, Academia, Academic institutions, Perspectives, India.

\section{Introduction}

India's economic growth in the last two decades has not been able to match its health indicators. ${ }^{1}$ Nearly 37 years ago, in 1978, the landmark Declaration of Alma-Ata, signed by nearly all member states of the World Health Organization and UNICEF, egressed a bold call for 'Health for All' by the year 2000 as part of the Global Strategy for Health for All. ${ }^{2}$ The underlying principle of 'Health for All' was Primary Health Care encompassing essential elements in the realms of public health, basic clinical services and health system as a whole working in tandem with other sectors like access to safe drinking water, agriculture, education, housing among others. The $65^{\text {th }}$ World Health Assembly held in Geneva in May 2012 identified Universal Health Coverage (UHC) as the key imperative for all countries to consolidate the public health advances. ${ }^{3}$ The WHO Member States have set themselves the target of developing their health financing systems to ensure universal coverage. Universal coverage means that all people can use health services, while being protected against financial hardship associated with paying for them. ${ }^{4}$

The Planning Commission of India constituted a high level expert group (HLEG) on UHC in October 2010 of achieving UHC for India by 2022. Ensuring equitable access for all Indian citizens, resident in any part of the country, regardless of income level, social status, gender, caste or religion, to affordable, accountable, appropriate health services of assured quality (promotive, preventive,

\section{Practice Points}

- Universal health coverage (UHC) is currently at the centre of efforts to strengthen health systems and requires concerted efforts from various range of stakeholders.

- The role of academia should duly be emphasized and their perspectives on advancing the agenda of UHC in India requires investigation.

- Concept of UHC and awareness on UHC developments was found low amongst stakeholders.

- Besides, tertiary care services, it was suggested emphasis on primary health care is more critical for UHC to succeed. Tax based and private health insurance that act complementary to each other, should be promoted to improve health services coverage.

- Findings suggest that there is a strong need for sensitizing and engaging the academia and academic institutions on UHC.

curative and rehabilitative) as well as services addressing the wider determinants of health delivered to individuals and populations, with the government being the guarantor and enabler, although not

Correspondence: Anjali Sharma, Program Officer, Public Health Foundation of India, Plot No. 47, Sec 44, Gurgaon-122002, Haryana, India. Email: anjali.sharma@phfi.org. 
necessarily the only provider, of health and related services. ${ }^{5}$

The major challenges in moving towards UHC have been cited as poor political will, weak performing health system, limited evidence for decision making and low government spending on health, among others. However, evidence also shows that low GDP has not been a hindrance in adopting, implementing and progressing towards UHC. Experience from low and middle-income countries, in Asia and Africa re-affirms that political will is the first and foremost for moving towards UHC. International experience shows that innovations like Brazil's expanded "right to health", Kyrgyzstan's Mandatory Health Insurance Fund, Mexico's "Seguro Popular" and Thailand's Universal Coverage scheme ${ }^{6}$ have successfully worked in achieving UHC in these countries. International experience with reference to reforms in large federal systems (for example, China and Mexico) also points out to dedicated attention on the role of local governments, with the centre using inter -governmental incentives to stimulate attention to health at state/provincial levels.

Experts believe that not enough time has been given for planning for UHC in India. ${ }^{6}$ Policy makers need to identify priority issues, key implementation challenges and main barriers, at the same time customising solutions across health system functions. The design and delivery of the UHC requires deep engagement of various range of stakeholders viz. policy makers, central and state governments, civil society, private sector, academia and health professional associations. However, very limited information is available and documented on the engagement of academia in advancing the agenda of UHC in India. Hence, the present study was designed to examine the perspective of academic leadership as UHC becomes the growing focus of global health and sustainable development.

\section{Materials and methods}

To gain the best possible insight into the engagement and perception of the academia for achieving the target of UHC, a cross-sectional qualitative study was undertaken. A semi-structured questionnaire developed by the authors, was emailed to 103 stakeholders out of which 62 responded. Snowballing approach along with convenience sampling was used for the selection of the study participants. The respondents included deans, senior faculty from department of community medicine and clinical departments from 17 government and 15 private medical institutions from 25 cities across India. Since the study involved getting the responses electronically through email, ethical approval was not obtained.

Data analysis was done through free listing of responses and domain evolution by elicitation of an exhaustive list of elements in a particular domain. Available responses for a particular question were listed to obtain the range of responses the responses for all open ended questions. Responses which were considered irrelevant under a specific question were moved under appropriate question. The responses obtained were scrutinized to identify and mark the pertinent sentences and expressions. Further on, a semi-quantitative qualifier was used to summarize the results and quantify the expressions of observations and the corresponding adjectives to describe them. ${ }^{7}$

\section{Results}

Majority of the respondents were aged 50 or more, having 25 or more than 25 years of experience, males and had affiliation with the private medical college. Respondents were involved in undergraduate and postgraduate teaching followed by research, administrative responsibilities, clinical work and training responsibilities. Some respondents also mentioned their involvement in consultancy, monitoring and evaluation of health programs and surgical work.

\section{Clarity on the concept of UHC}

More than half of the respondents opined that there is a difference in philosophy of Health for All and UHC. Health for All broadly was opined as attainment of level of health that will permit all people to lead economically and socially productive life, not necessarily explaining the coverage of assured services and the specific mechanism through which the services will be delivered. While UHC was described as 'financial protection' with services being provided at affordable cost, so that people do not suffer financial hardship in the pursuit of good health, and 'protection of patient's

Table 1: Qualifiers used for semi-quantitative expression of observations ${ }^{7}$

\begin{tabular}{|c|c|c|}
\hline $\begin{array}{c}\text { Respondents } \\
(\mathbf{\%})\end{array}$ & Qualifiers & Adjectives Used \\
\hline$<10 \%$ & $<1+$ & Very Few \\
\hline $11-24 \%$ & $1+$ & Some \\
\hline $25-49 \%$ & $2+$ & Approximately $1 / 2$ \\
\hline $50-74 \%$ & $3+$ & Majority/Over $1 / 2$ \\
\hline $75-89 \%$ & $4+$ & Most \\
\hline$\geq 90 \%$ & $5+$ & Almost all \\
\hline
\end{tabular}

Table 2: Socio-demographic characteristics of study subjects

\begin{tabular}{|l|c|}
\hline Variables & $\begin{array}{l}\text { Respondents } \\
\text { (n=62) }\end{array}$ \\
\hline Age (years) & 25 \\
\hline$<50$ & 37 \\
\hline$\geq 50$ & 55 \\
\hline Gender & 7 \\
\hline Male & \\
\hline Female & 32 \\
\hline Departments & 30 \\
\hline MD/PhD in Community Medicine & \\
\hline $\begin{array}{l}\text { Others (MS/other clinical } \\
\text { departments) }\end{array}$ & 27 \\
\hline Affiliation & 35 \\
\hline Government & \\
\hline Private & 32 \\
\hline Work experience (years) & 30 \\
\hline$<25$ & \\
\hline$\geq 25$ & \\
\hline
\end{tabular}


rights' that guaranteed appropriateness of care, patient choice, portability and continuity of care. It was felt that UHC is the means of attaining Heath for All. Additionally, it was put that in the case of UHC, prepayment of funds is done to reduce direct payments in case of emergency which is not present in HFA. The relation between HFA and UHC was described as HFA is an epistemologic goal and UHC is an ontology for implementation.

"UHC aims that all people get essential/required health services at all the health care delivery centres with any financial bondage. For this, we require strong and efficient health system, financial assistance, free delivery provision for all essential drugs, easy access to latest technology, well trained nursing staff and health worker. Easy access to health services enable people to be more productive and active contributor to community and their family. The fact is that poor is more likely to get disease and spending more money at their health facility pushes them into extreme poverty so this will creates a cycle of poverty and disease. We will break this only through universal health coverage. Only through UHC social inequality can be minimized." (Professor \& Head, Department of Community Medicine)

"HFA is a very broad goal of doing good to all without any practicably financial roadmap as to how to go about it. UHC strives to provide that road-map." (Prof, Department of Medicine)

\section{Awareness regarding UHC developments in India}

Approximately half of the respondents were not aware about any development regarding UHC in India. Over half of them cited that they do have some knowledge about recent developments related to UHC in India. Various thoughts on developments that were shared were India's engagement with UHC started from Bhore Committee in 1946 to Vision $2020^{5}$ but got faltered because of various reasons including resource constraints. Other developments that were cited included: Public Private Partnership Program under NRHM $^{8}$; Rajeev Gandhi Jeevandayi Yojana, ${ }^{9}$ a health insurance scheme; and Adhar Yojana, ${ }^{10}$ a social security scheme.

Approximately half of respondents had not read any reports or a publications on UHC in India. However, over half of the respondents did mention reading some UHC reports or publications on UHC. Most cited the High Level Expert Group (HLEG) report ${ }^{5}$ followed by the UHC series ${ }^{11}$ and editorials published by the Lancet. Almost all the respondents expressed interest in knowing more on UHC and getting engaged in discussions related to UHC. However, it was also conveyed that:

"The discussions need to happen at the point of care and not just remain confined to the policy making temples. " (Professor, Department of Medicine)

"TB Program has changed the policy by putting down targets to universal coverage. The insurance schemes of the government is getting more and more poor..." (Professor, Department of Community Medicine)

\section{Stakeholders for achieving UHC in India}

The respondents suggested the engagement of following stakeholders is critical: Central and State governments, Non-Governmental organizations (NGOs), Civil Society organizations, community and faith based organizations, voluntary organizations, government and private hospitals, health care providers in public and private sector viz. doctors, allied health professionals, AYUSH, and other health professionals. Other diverse groups that emerged out from the responses were health administrators, health care managers, academicians, management groups, media, insurance sector, finance organizations, representatives from pharmaceutical sector, allied sectors like sanitation, environment etc. Last but not the least policy makers and committed and accountable political leaders for ensuring political will. Several professional bodies and councils that can be involved in the UHC related discussions were also put forth like public health associations like Indian Association of Preventive and Social Medicine (IAPSM) \& Indian Public Health Association (IPHA), domain specific associations like Indian Academy of Paediatrics, Federation of Obstetric and Gynaecological Societies of India (FOGSI), Association of Nursing Personnel, Indian Medical Association (IMA), the Associations of Physicians of India, Medical Council of India (MCI), Voluntary Health Association of India, health insurance providing bodies, and other NGOs and institutions.

"Strongly committed, responsible and accountable politicians-Who are the supreme visionaries in Indian Democracy... those who believe in pure foresighted development and not in the dirty politics!" (Professor and Head, Department of Community Medicine)

Academic institutions - an important stakeholder in discussion related to $U H C$ ?

Almost all of the respondents said that they have not received any information on issues related to UHC. Most of the respondents denied being ever called for any meeting/policy discussions on UHC.

Almost all the respondents concurred that there is a need to engage their organization or similar organization in discussion on UHC. Arguments that were quoted to support this were:

"Our centre is a tertiary care centre and sufficient infrastructure and adequate manpower is available and can contribute to UHC." (Professor and Head, Department of Community Medicine)

"The private medical colleges in general are not called for any dialogue with the government on health care delivery." (Professor and Head, Department of Community Medicine) 
"UHC Recommendation.No.3.3.2 - Enhance the quality of HRH education \& training by introducing competency based health system connected curricula and continuous education. In this regard my organization is going to play very crucial role to plan and execute for health professional education need as recommended in UHC at SHC (BRHC), PHC, CHC, DHC and apex center." (Professor and Head of Department, Department of Community Medicine)

"We are a private health sciences university and already running some community insurance schemes... we do have some experience in this regard. And can contribute to the discussion of UHC." (Professor, Department of Psychiatry)

Respondents expressed their interest in contributing for provision of services and making health services accessible and affordable to the needy people. It was felt that for UHC, affordability is crucial and thus medical colleges can provide care to people who cannot afford. The respondents believed that their organization is actively engaged in delivery of health care at the tertiary, secondary and primary care level and therefore can provide UHC of their catchment area. Approximately half of the respondents said their organization can support the provision of providing promotive, preventive, curative and rehabilitative health services to achieve UHC.

Approximately half of the respondents also expressed contributing towards the training of manpower, capacity development and developing HRH for generating more manpower and providing appropriate health care at different levels. Implementation of UHC and monitoring and evaluation of various national health programs were also some activities that were proposed. Providing community-based insurance, giving access to essential drugs, vaccines and medical technology, telemedicine were also brought forth.

Respondents also opined that their organization can contribute in training of health professionals specifically the medical doctors as they are well aware of their district's health challenges. It was implied from some of the responses that medical education and health care services of the state should be integrated. For example:

"Departments of community medicine is having Urban Health Training Centre and Rural Health Training Centre as field practice areas for training of health professionals and providing health care to people. There should be positive will to integrate medical education and health care services of the state for better output. But unfortunately today we are experiencing watertight compartments. In my opinion MBBS and MD students should be educated as per the demands of UHC to discharge their duties when they occupy the key chairs. The laboratory of Community Medicine is in the field under health care services and not within four walls of ivory towers of medical colleges." (Professor and Head of Department, Department of Community Medicine)
The Government's role in providing UHC to Indian citizens

Almost all of the respondents said that it is indeed the government responsibility to provide UHC to Indian citizens. It was reaffirmed that health is a basic human right and the state has a major responsibility in providing this need to all its citizens. However, the role of private sector and collaborations was certainly not overlooked with the private sector, NGOs being equally accountable.

It was felt that government should provide financial support to the organizations providing UHC viz. subsidy, technical, manpower, infrastructural and logistic support to make the program sustainable. Training and capacity building was also one component that was emphasized for efficient health delivery. HRH reforms with clear policy including incentive/disincentive system with better remuneration to those who perform better was brought forth.

It was also thought that giving insurance coverage to all the Indian citizens at affordable cost, increasing health financing for public sector, monitoring, providing basic laboratory facilities at all the health centres, cost and access to essential medicines, vaccines, technology and equipment are important for which government needs to support to move closer to UHC.

Almost all of the respondents urged that that the government should proactively engage with public institutions like theirs on discourse on UHC. Willingness to listen to the private medical colleges and their ability to transform the district by involving them was also pointed out. Last but not the least, Government's commitment, leadership and accountability at all levels was cited as the bottom line for UHC to be a reality.

"Government medical colleges \& hospitals should be integrated in UHC and not to be separated from health services with special involvement of department of community medicine for training, evaluation and research purposes." (Associate Professor, Department of Medicine)

\section{Health Services: Tertiary care Vs primary care}

Almost all of the respondents strongly believed that not only the tertiary care services but the primary health care is more important for UHC to succeed. Tertiary care services were viewed more investment intensive in infrastructure, equipment and manpower development. Strengthening of primary health care was recommended by ensuring adequate human resources, logistics, and accessibility. They are complementary to each other, good primary and secondary care adds to good tertiary care and thus it will fulfil the goal of essential health coverage to all the Indians.

Some of the respondents also felt that all the three are equally important since beneficiaries of different care levels are different. However very few respondents felt that tertiary care services are more important in achieving UHC. Reasons cited were the movement on a 
cost to person basis the probability of catastrophic expenditure is higher for secondary and tertiary health care interventions for the common man than that for primary health care services.

A respondent commented:

"It is a ladder of health care services, if primary care is neglected, we land in provision of secondary care and if this is ignored we have to provide tertiary health care. Therefore more stress should be on primary followed by secondary and tertiary health care." (Associate Professor, Department of Medicine)

\section{Defined benefit package}

Majority of the respondents felt that a defined benefit package is important to improve efficiency and quality of service delivery and shall help in improving the utilization of health services.

"It will help to protect the interest of marginalized and poor segment of society." (Dean and Director, Department of Community Medicine)

But it was pointed out that the package must match the needs of community, gender and age specific to suit local needs and problems in order to protect the interest of marginalized and poor segment of society.

"It is better because it makes the service more structured, object oriented and improves ease of delivery. At the same time, it should not be a watertight package...there should be reasonable flexibility to accommodate special cases." (Head, Department of Biostatistics \& Medical Informatics)

However, some respondents disagreed the utility of a defined benefit package, various reasons cited - not workable in vast country like India:

"No, a defined package shall not be useful. A benefit package should be designed as per client needs." (Professor \& Head of the Department, Department of Obstetrics and Gynaecology)

"This will lead to overutilization and extra expenditure on unnecessary investigations, drugs and procedures. Regionalized health care is a better way with appropriate referrals." (Associate Professor, Department of Community Medicine)

"Defined benefit package will not work in a vast country like India. We have to develop local packages to suit local needs and problems." (Professor, Department of Community Medicine)

Very few said "May be".

"Beneficial to a certain extent as in the case of Rastriya Swasth Bima Yojana, Janani Shishu Suraksha Karyakaram and others." (Professor \& HOD, Department of Orthopaedics)
Services to be included in UHC package

Approximately half of the respondents mentioned promotive, preventive, curative and rehabilitative services, eight elements of primary health care, secondary and tertiary care services should be included in the UHC package. Besides these, services for communicable and non-communicable diseases, immunization services, diagnostic services, antenatal care, postnatal care, emergency referral, transportation services were also stressed on. Access to safe drinking water, adequate sanitation, education, environment safety and other underlying determinants of health were also considered important.

Health financing: Health services at point of care affordable cost or no cost?

Majority of the respondents felt health services should be provided free at the point of care. However, it was also added that this can be implemented taking into account the socio-economic strata with the basic services being free of cost for poor and marginalized, Below Poverty Line (BPL) groups whereas in higher socio-economic groups, user fees can be charged.

"In backward/low socio-economic groups and in higher socio-economic groups user fees can be charged." (Prof $\&$ Head, Department of Community Medicine)

While others felt that health services should be free for all at the point of care and the funds should be generated by increasing the direct and indirect taxes and by increasing the number of people paying taxes. Basic preventive and curative services, were felt, should be free. Subsidy can be provided for non-preventable conditions. However, on other hand, approximately half of respondents said that health services should not be provided free at the point of care. They should be charged which the community could afford easily. Another approach that was put:

"Every individual should give 1-2\% of their income and rest should be provided by government for paying insurance premium." (Dean \& Professor, Department of Pathology)

"Health services should be free for all at the point of care and the funds should be generated by increasing the direct and indirect taxes and by increasing the number of people paying taxes." (Dean and Senior Professor, Department of Anaesthesiology)

It was also proposed that all emergency lifesaving services should be free.

Tax based public financing vs. Insurance - private health insurance

Approximately half of the respondents believed that government should promote public health insurance for better universal coverage and equity but also proposed that there should be proper monitoring so that funds reach to the needy. However it was suggested that it should be provided at minimum amount and can be made compulsory for all citizens. Some respondents felt 
that private health insurance is more beneficial and if done under strict supervision, has the capacity to regulate the health market in India where $70 \%$ health care is in private hands. Approximately half of respondents also concurred that both public as well private health insurance should be promoted by government and they should be complementary to each other to improve health coverage and control any corruption. The ulterior responsibility to ensure that all the citizens are covered by some health insurance was viewed with the government.

Some of the responses of the respondents are as follows:

"It should be a mixed model in order to reduce the risk (i.e. spread the financial risk) and ensure sustainability; both should be complementary to each other." (Assistant Professor, Department of Paediatrics)

"Public insurance is a drain on the tax payer; private insurance with good governance, good assurance, less red tapism will help in larger and faster coverage." (Dean and Professor, Department of Radiology)

\section{Discussion and Conclusion}

The first wave of UHC came in the 19th century after German Chancellor Otto von Bismarck introduced comprehensive medical care that covered large segments of blue-collar workers. Germany's 1883 Health Insurance Bill and other social legislations formed the basis of the modern welfare state. The next wave of UHC is in India, China and other emerging economies. ${ }^{12}$ Subsequent to the $12^{\text {th }}$ Plan, there has been a renewed focus in India on the how to deliver UHC emphasizing on the quality and distribution of existing health programs, appropriate roles of the public and private sectors, local and central governments entitlements for sick, healthy, rich and poor population. ${ }^{13}$

Although UHC is a global health policy priority, there remains limited evidence on the role the academic community can play in bringing UHC reforms. Academia represents an important stakeholder and findings from the study indicate they are quite willing to contribute and engage in policy dialogue and UHC implementation. Findings suggest that there exists a dire need to sensitize academia and academic institutions on $\mathrm{UHC}$ and develop mechanisms and processes on how they can be efficiently engaged. Academia and academic institutions can be considered the focal point for UHC training and UHC related health services. Debates continue on the role of private sector involvement; ${ }^{14}$ however, their participation should not be overlooked. Public private partnerships should be explored.

It was also pointed out that accreditation for health care packages and support for infrastructure development is a must for uniform standards. There is no magic pill to achieve UHC and it can't be achieved in isolation; likewise education should not be seen in isolation, rather it ought to be taken as a path for reform. UHC requires a deep engagement and coming together of all the stakeholders including academia to ensure quality health services to all people, without pushing them into financial hardship. The data makes evident that $\mathrm{HRH}$ education calls for a revisit in order to support UHC. Academicians are engaged with health professional education and training which forms the backbone of health care delivery under UHC. Health professionals should be educated as per the demands of UHC to discharge their duties. At the university level, there is the agenda on curriculum improvement; at the professional level, the pursuit of lifelong learning; and at the health systems level, the establishment of linkages and relationships. ${ }^{14}$ It is important to note that these factors should work altogether to achieve the goal of UHC.

\section{References}

1. Reddy S. Universal Health Coverage for India: Dream or Development Imperative? http:// www.lilafoundation.in/2013/12/27/srinath-reddyuniversal-health-coverage-india-dreamdevelopment-imperative/ (accessed Dec 2015)

2. World Health Organization. Global Health Declarations. http://www.who.int/trade/glossary/ story039/en/ (accessed Dec 2015)

3. Singh, Z. Universal health coverage for India by 2022: a utopia or reality? Indian J Community Med 2013; 38(2): 70-3.

4. World Health Organization. 10 Facts on Universal Health Coverage. http://www.who.int/ features/factfiles/universal health coverage/ facts/en/ (accessed Dec 2015)

5. Planning Commission of India. High Level Expert Group Report on Universal Health Coverage for India. New Delhi: Planning Commission of India, 2011.

6. Duran A, Kutzin J, Menabde N. Universal coverage challenges require health system approaches; the case of India. Health Policy 2014, 114(2-3):269-77.

7. Arora NK. IndiaCLEN Family Health Awareness Campaign (Summer 2000) Program Evaluation. New Delhi: IndiaCLEN Program Evaluation Network Central Coordinating Team on behalf of IndiaCLEN Program Evaluation Network (IPEN), 2000.

8. Programme Evaluation Organisation. Evaluation Study of National Rural Health Mission (NRHM) in 7 States. Planning Commission, Government of India, 2011.

9. Rajiv Gandhi Jeevandayee Arogya Yojana. https://www.jeevandayee.gov.in/. (accessed Jan 2016) 
10. Unique Identification Authority of India. https:// e n. w i k i p e d i a.org/ w i k i / Unique Identification_Authority_of_India (accessed Jan 2016)

11. The Lancet. http://www.thelancet.com/journals/ lancet/issue/vol380no9845/PIIS0140-6736(12) $\underline{\text { X6037-9 }}$ (accessed Jan 2016)

12. Huang, Y. World Momentum Builds for Universal Health Coverage. Yale Global Online, March 9 2012. http://yaleglobal.yale.edu/content/ world-momentum-builds-universal-healthcoverage (accessed Feb 2016)
13. Rawat, BS. Lov Verma stress on the need to hike public spending on basic healthcare. Drug Today Medical Times, 16 Sept 2014. http:// www.drugtodayonline.com/medical-news/ nation/1201-lov-verma-stress-on-the-need-tohike-public-spending-on-basic-healthcare.html. (accessed Feb 2016)

14. HealthSpace.Asia. Summary of sessions regarding $5 \mathrm{C}^{\prime} \mathrm{s}$ works in the 6th AAAH Annual Conference, November 23, 2011. http:// healthspace.asia/profiles/blogs/summary-ofsessions-regarding-5c-s-works-in-the-6th-aaahannual-c (accessed Feb 2016). 